\title{
Seismic Performance Analysis of Continuous Rigid Frame Bridges in Expressway under Non-linear Interactions of Soil- Piles
}

\author{
Yongbing $\mathrm{FENG}^{1, \mathrm{a}}$ \\ ${ }^{1}$ CCCC Infrastructure \\ Maintenance Group CO., LTD., 100011 Beijing, China
}

\begin{abstract}
Taking the three-span pre-stressed concrete continuous rigid frame bridge as an engineering example, MIDAS Civil was utilized to establish a spatial finite element model and the interaction between pile foundation and the soil was simulated by equivalent soil spring. In addition to analyzing shearing force, bending moment and stress of the primary beam's characteristic section under different loads, a response spectrum method and time history analysis were adopted to conduct seismic response analysis respectively. In this case, performance of the bridge could be comprehensively evaluated. Relevant analysis results indicate that internal force of the large-span pre-stressed concrete continuous rigid frame bridge is mainly induced by gravity and pre-stress of the structure; section stresses of the primary beam satisfy the corresponding specification and structural safety can be achieved in a state of operation. Moreover, computed results obtained by the response spectrum method is more conservative than those of the time history analysis. In terms of continuous rigid frame bridge, different seismic directions should be taken into consideration during structural seismic analysis at different construction stages.
\end{abstract}

\section{Introduction}

Pre-stressed concrete continuous rigid frame bridge is featured with light and graceful structure, beautiful shape, great spanning ability and high riding comfort, etc. Without any doubt, it has become the preferred bridge type in mountainous areas where the expressway needs to step over terrain such as canyons. A continuous rigid frame as a pier beam consolidation system. Responses of the continuous rigid frame bridge and the ordinary beam bridge to earthquake are significantly different from each other. According to the phase difference of seismic waves and the behavior of foundation soil layers, Sh.X. Zhang and Sh.Zh. Xi et al. [1] investigate their influence on rigid frame bridge; D.Sh. Zhu and Sh.Zh. Liu et al. [2] analyze impacts of pier beam joining type and radius of curvature, etc. on seismic responses of the continuous beam bridge; and, as for X. Li and K.H. Wang et al. [3], response spectrum method and time history analysis combining the influence of interactions between soil and foundation on bridge pier are utilized to analyze differences in seismic responses between continuous rigid frame compounding bridge and the continuous rigid bridge. Under the circumstance of bridge construction design for high intensity seismic zones, dynamic characteristics should be taken into account to analyze anti-seismic property of the structure in detai. In this paper, three-span pre-stressed concrete continuous rigid frame bridge was taken for example and then the equivalent soil spring was selected to simulate

\footnotetext{
*Corresponding author: ${ }^{\text {a frbeesky } @ 163 . c o m ~}$
}

interactions between the soil and the pile work; then, a spatial finite element model was set up in line with the construction procedures to analyze static and dynamic characteristics of the structure. In combination with seismic wave characteristics of the site, the response of E2 to the earthquake was determined by time history analysis and earthquake response spectrum analysis. Furthermore, not only were response values acquired through different computing methods analyzed, but antiseismic property of the bridge was profoundly investigated.

\section{Engineering Situation}

Expressway in a mountainous area is constructed according to a bidirectional four-lane standard with design speed of $80 \mathrm{~km} / \mathrm{h}$ and roadbed width of $25.5 \mathrm{~m}$. Under the circumstance of stepping over a V-shaped canyon, a three-span pre-stressed concrete continuous rigid frame bridge with variable cross-section as shown in Figure 1 is adopted. Its span is arranged as $65 m+110 m+65 m$ and the main bridge is $240 m$ long. Superstructure of the main bridge is a three-way prestressed concrete box girder with simple-box simple-cell section. In addition, the box girder is a straight web of variable height; width of a single top slab and a bottom slab is $12.5 \mathrm{~m}$ and $6.5 \mathrm{~m}$ respectively; length of its cantilever is $3.0 \mathrm{~m}$, thickness of its cantilever slab end and root is $0.18 \mathrm{~m}$ and $0.65 \mathrm{~m}$ separately; beam depth of 
central pier fulcrum is $6.5 \mathrm{~m}$; and, beam height of end fulcrum and the min-span is $2.8 \mathrm{~m}$. Inside the box, bottom slab of the straight section is 0.3 thick and that of central pier fulcrum is $1.0 \mathrm{~m}$ thick; beam height and bottom slab thickness change according to second degree parabola; excluding support beam, top slab of the box girder is $0.8 \mathrm{~m}$ thick and the remaining part is $0.3 \mathrm{~m}$; web thickness on the horizontal section and variable beam height section respectively is $0.45 \mathrm{~m}$ and $0.75 \mathrm{~m}$; moreover, both the central fulcrum and the end fulcrum are thickened to $1 \mathrm{~m}$ and $1.25 \mathrm{~m}$ respectively. The main pier is a double thin-wall pier. Cross section for a single batten of the pier body is $6.5 \mathrm{~m} \times 1.2 \mathrm{~m}$ and clear distance between piers is $3.5 \mathrm{~m}$. While the main pier is a pile group foundation, the bearing platform is rectangular with a plan view size of $8.2 \mathrm{~m} \times 7.0 \mathrm{~m}$; besides, the corresponding thickness is $3.5 \mathrm{~m}$ and 4 cast-in-place pile foundations as deep as $2.0 \mathrm{~m}$ are arranged below each bearing platform.

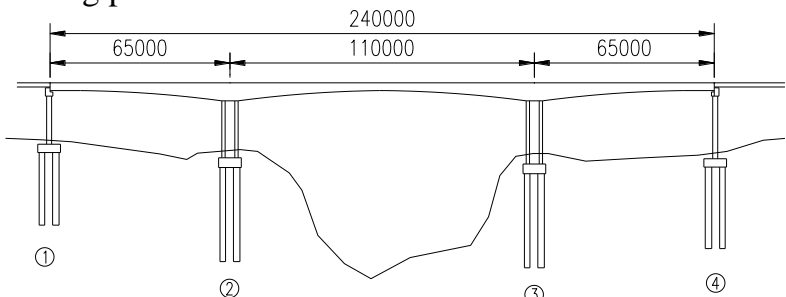

Figure 1. General Layout Diagram of Main Bridge (Unit: mm)

\section{Full-bridge Finite Element Model}

According to beam segment division during construction, MIDAS Civil was utilized to establish a threedimensional finite element model for the bridge, as shown in Figure 2. While space beam elements were suitable for the main beam, general beam elements were used for bridge piers, bearing platforms and pile foundations. Pre-stressed steel beam simulation was implemented by exerting pre-stressed load and pier beam consolidation is realized by rigid connection. For the consideration of mutual effects between bridge pile foundation and soil, equivalent soil spring simulation was adopted [4-7]. The full bridge contains 392 elements and 415 nodes. Regarding the main beam, the bridge pier and the bearing platform and pile foundation, C50 concrete, C40 concrete and C30 concrete were selected accordingly.

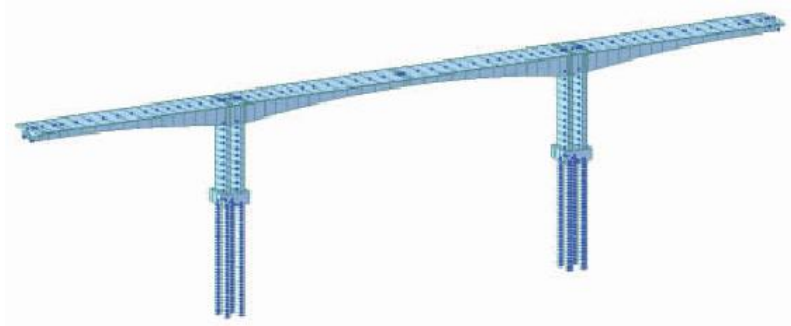

Figure 2. Full-bridge Finite Element Model

\section{Structural Characteristics Analysis}

\subsection{Analysis on Static Characteristics of Structure}

Actual bearing capacity of the main beam under loads was analyzed from three perspectives of shear force, bending moment and stress.

Dependent on shearing force diagram of the main beam in in-service stage (Figure 3), it can be seen that shearing force of the large-span continuous rigid frame bridge is mainly incurred by self-weight and pre-stress; percents occupied by pre-stressing effect in gravitational force of the structure on min-span position of the side span, on cross sections adjacent to the pier top and on min-span position of the mid-span are $-54.04 \%, 116.80 \%$ and $57.05 \%$ correspondingly. Therefore, not only should structural stress of the mid-span section be taken into sufficient account during structural design, but shear strength of the corresponding section is checked.

By analyzing bending moment diagram of the main beam in its in-service stage (Figure 4), it can be seen that bending moment of the main beam for a large-span continuous rigid frame bridge is principally incurred by gravitational force of the structure and the pre-stress; however, bending moments separately caused by the gravitational force and the pre-stress mentioned above have opposite directions. Additionally, bending moment incurred by the pre-stress occupies $-48.25 \%$ on min-span position of the side span, $-63.17 \%$ on cross sections adjacent to the pier top and $-201.82 \%$ on min-span position of the midspan in gravitational effect of the structure. For this reason, pre-stressed steel beams must be rationally arranged and the influence of pre-stressing effects on gravitational force of the structure be sufficiently considered in the course of design.

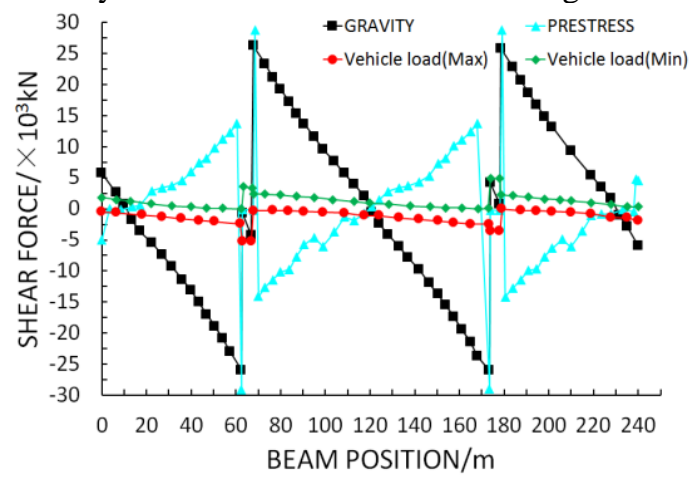

Figure 3. Shearing Force of the Main Beam

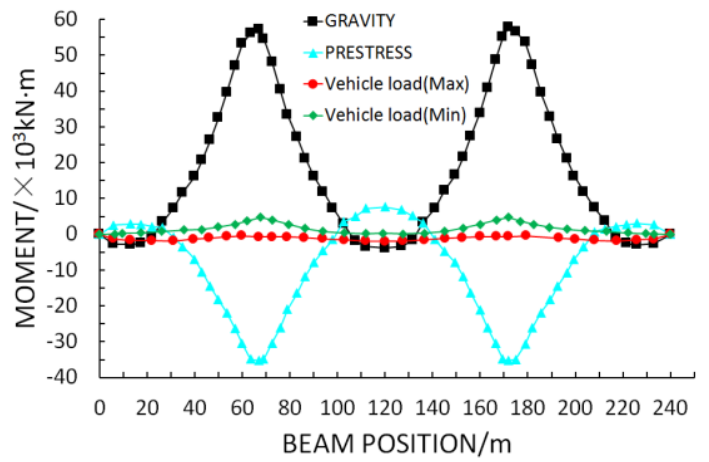

Figure 4. Bending Moment of Main Beam 
In operation stage of the completed bridge, its safety is directly related to strength and stress of the main beam. Analysis indicates that maximum compressive stresses on normal and oblique sections of the main beam are 13.29MPa and $13.49 \mathrm{MPa}$ respectively, which conforms to the requirements of specification. As demonstrated by computed results, stresses on all sections of the main beam are up to the standard of specification and the structure can serve safely in practice.

\subsection{Analysis on Dynamic Characteristics of Structure}

Comparing with dynamic structural analysis subjected to a dynamic processing method of static displacement, resistance coefficient of foundation soil is usually higher than that obtained by static analysis. In this paper, dynamic characteristics analysis was carried out for bridge structure in the case that $\mathrm{m}_{\text {Dynamic }}=2.5 \mathrm{~m}_{\text {Static }}$ where $\mathrm{m}$ refers to the foundation coefficient. To ensure effective mass achieved from the direction of calculation exceeded $90 \%$, mode of vibration of the first 120 orders was analyzed. In Table 1 below, only that of the first 8 orders has been listed.

Table 1. Natural Frequency and Mode Characteristics of the Bridge

\begin{tabular}{|c|c|l|}
\hline $\begin{array}{c}\text { Ord } \\
\text { er }\end{array}$ & $\begin{array}{c}\text { Frequency } \\
\text { (Hz) }\end{array}$ & \multicolumn{1}{|c|}{ Mode Description } \\
\hline 1 & 0.511 & $\begin{array}{l}\text { Longitudinal vibration of bridge pier; } \\
\text { longitudinal drifting of main beam }\end{array}$ \\
\hline 2 & 0.566 & $\begin{array}{l}\text { Anti-symmetrical crook of bridge pier; } \\
\text { anti-symmetrical transverse vibration of } \\
\text { main beam }\end{array}$ \\
\hline 3 & 0.604 & $\begin{array}{l}\text { Symmetrical crook of bridge pier; } \\
\text { symmetrical transverse vibration of } \\
\text { main beam }\end{array}$ \\
\hline 4 & 0.703 & $\begin{array}{l}\text { Symmetrical crook of bridge pier; } \\
\text { symmetrical transverse vibration of } \\
\text { main beam }\end{array}$ \\
\hline 5 & 1.228 & $\begin{array}{l}\text { Symmetrical crook of bridge pier; } \\
\text { symmetrical transverse vibration of } \\
\text { main beam }\end{array}$ \\
\hline 6 & 1.782 & $\begin{array}{l}\text { Symmetrical crook of double batten for } \\
\text { the bridge pier }\end{array}$ \\
\hline 7 & 2.098 & $\begin{array}{l}\text { Anti-symmetrical crook of double } \\
\text { batten for the bridge pier }\end{array}$ \\
\hline 8 & 2.508 & $\begin{array}{l}\text { Anti-symmetrical crook of bridge pier; } \\
\text { anti-symmetrical transverse vibration of } \\
\text { main beam }\end{array}$ \\
\hline
\end{tabular}

According to the figure above, it is clear that fundamental frequency of the structure is $0.511 \mathrm{~Hz}$, vibration modes of the first 8 orders are embodied in longitudinal drifting and lateral bending vibration of main beam and vibration modes of different orders are rather simple, which are major representations of continuous rigid frame bridge system.

\section{Seismic Analysis on the Structure}

\subsection{Response Spectrum Analysis on Static}

The project belongs to Type II site where seismic fortification intensity of the bridge is 7 , ground motion peak acceleration is $0.15 \mathrm{~g}$ and characteristic cycle of Class B bridge is $0.4 \mathrm{~s}$. According to detailed regulations on aseismic design of bridge, damping ratio was defined as 0.05 for the bridge. As for beam bridges with unconventional configurations, a multi-mode response spectrum approach could be selected for seismic analysis on E1 geological processes. Relevant computational formula given in the existing aseismic design rules of China is:

$$
S_{\max }=2.25 C_{i} C_{s} C_{d} A
$$

based on which, $S_{\max }$ referring to the maximum acceleration of horizontal design can be figured out. In this equation, $C_{i}$ stands for seismic importance factor, $C_{s}$ for site coefficient, $C_{d}$ for damping adjustment coefficient, and $A$ for the basic seismic peak acceleration for horizontal design.

After geological processes along the axial direction of bridge and its transverse and vertical directions have been taken into sufficient consideration, different modes of vibration can be combined in a form of CQC. As regards the combined geological process components, they can be calculated by means of SRSS.

\subsection{Linear Time History Analysis}

On account of features of type II site, three known strong shock earthquake waves were selected for time history analysis. Their effective peak acceleration is $0.377 \mathrm{~g}$, $0.079 \mathrm{~g}$ or $0.948 \mathrm{~g}$. Subjected to E1 geological process, peak adjustment coefficients in horizontal direction of such three waves are $0.172,0.822$ and 0.068 ; by contrast, these values turn into $0.519,2.490$ and 0.206 in terms of E2 geological process. During dynamic time history analysis, initial state was defined to be dead load. Meanwhile, sufficient considerations were given to geological processes in axial direction and transverse direction of the bridge [8-10].

\subsection{Seismic Analysis Results}

Seismic response analysis was performed for the bridge by response spectrum method and time history analysis. Under the action of E2 geological process, shearing forces on all pier tops and bottoms have been shown in Figures5-6 and relevant bending moments presented in Figures 7-8. By comparing Figures 5-8, it can be proven that the law of computed results achieved by the response spectrum method and the time history analysis is consistent, despite that a certain difference lies in total percentage and both shearing forces and maximum bending moment response values figured out by the former are greater than those achieved by the latter. To be specific, shearing force worked out for longitudinal earthquake loadings by virtue of the time history analysis takes approximately $70.0 \%$ in that by the response spectrum method; with regard to the associated bending moment values, they dramatically vary from $65.0 \%$ to $92.0 \%$. In terms of transverse earthquake loadings, 
shearing force obtained by time history analysis is $70.6 \%$ $-86.9 \%$ of that figured out by response spectrum analysis; regarding bending moment, it lies between $70.8 \%-87.4 \%$. This demonstrates that results acquired by response spectrum method are more conservative than those by time history analysis as far as the bridge is concerned; and, from the angle of structural safety, response spectrum method should be employed for the bridge to conduct seismic performance design and checking.

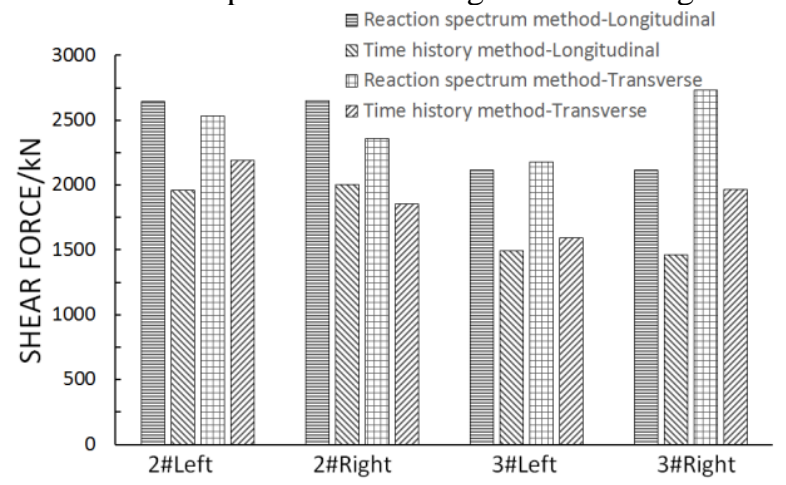

Figure 5. Maximum Shear Response on Pier Top in E2 Geological Process

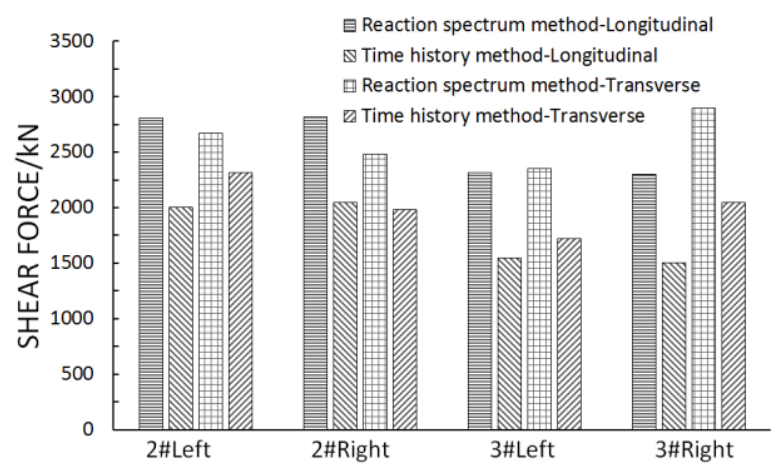

Figure 6. Maximum Shear Response on Pier Bottom in E2 Geological Process

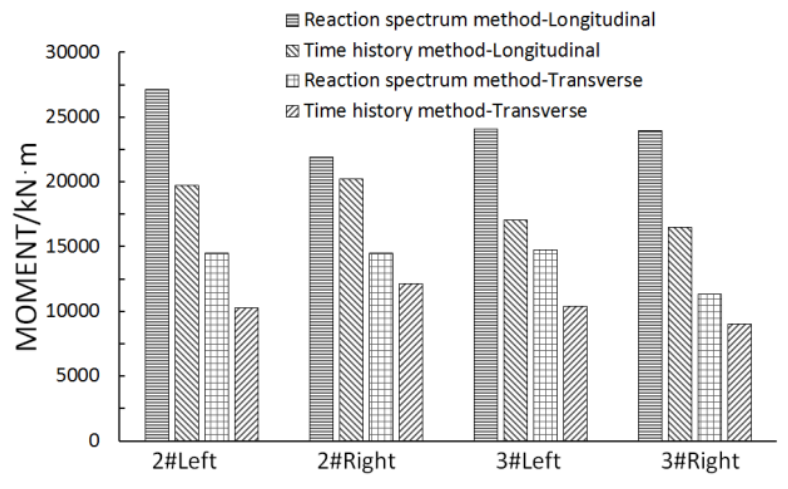

Figure 7. Maximum Bending Moment Response on Pier Top in E2 Geological Process

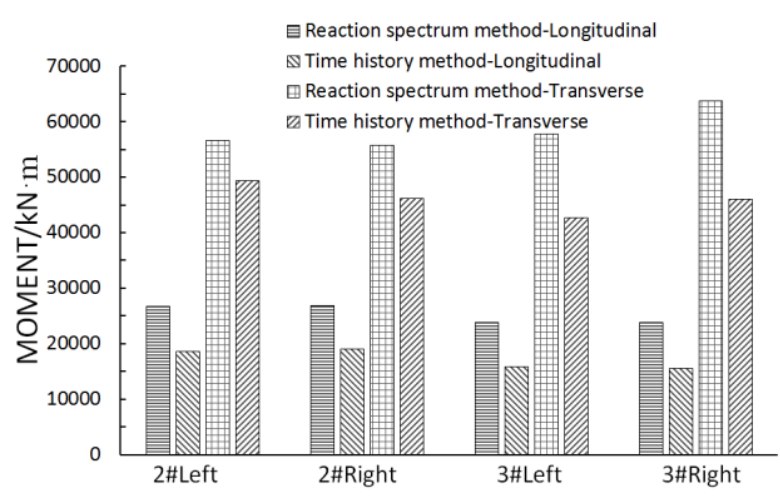

Figure 8. Maximum Bending Moment Response on Pier Bottom in E2 Geological Process

\subsection{Seismic Analysis on the Maximum Cantilever Construction Stage}

In comparison with traditional bridge structures, continuous rigid frame bridge has higher seismic behavior. However, T-shaped structure can be very dangerous before closure. Under the influence of earthquake, it can substantially damage pounding bottom of the pier and consolidation position of the pier beam [11]. Main piers 2 and 3 of the bridge have been built in a similar way to superstructure. Therefore, only main pier 3 was selected to investigate state of the largest cantilever segment. According to the existing earthquake resistant design code for bridges and culverts of China, while self-weight of the structure, hanging basket construction loads and pre-stressed loads, etc. should be considered at the construction stage, factors needing considering at the completed bridge stage cover selfweight, secondary dead load and pre-stressed loads, etc., in the event of utilizing response spectrum method to calculate internal force of the structure subjected to E2 geological process.

Internal force of pier 3 has been shown in Figures 910. Based on the geological process along axial direction of the bridge, shearing force at the maximum cantilever state during construction compared to that at the completed bridge stage reduces by $15 \%$ approximately; and, the relevant bending moment lowers by about $8.91 \%-19.8 \%$. In a geological process along the transverse direction of the bridge, by contrast, the increase in shearing force at the maximum cantilever state during construction ranges between $0.3 \%$ and $21.5 \%$ and the related bending moment rises by $16.7 \%$ $38.3 \%$, if compared with those at the completed bridge stage. It signifies that shearing force and bending moment incurred by earthquakes along the axial direction of the completed bridge are dominating factors of pier 3 so that earthquake resistance in the axial direction of the bridge should be sufficiently considered; as for the pier 3 in the maximum cantilever state of construction, shearing force and bending moment are generated by earthquakes in the transverse direction of the bridge, in which case, analysis on earthquake resistance in the axial direction of the bridge should be conducted for this stage. In terms of continuous rigid frame bridges, geological process directions taken into 
account during seismic analysis on their structures are different in various stages of construction.

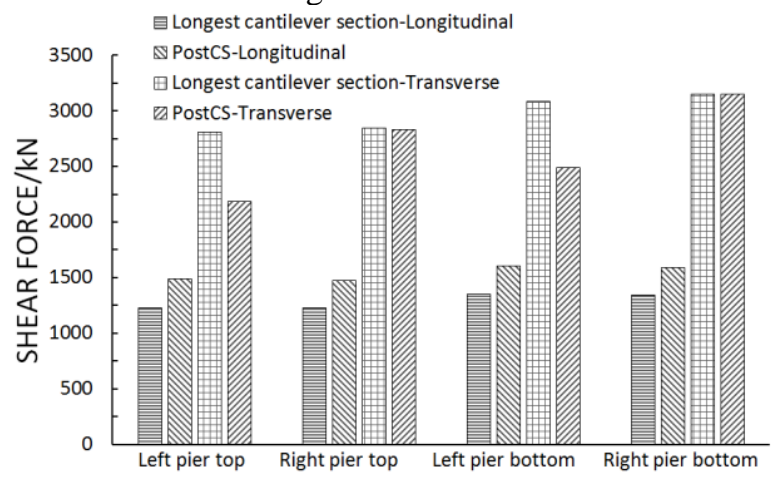

Figure 9. Shearing Force of Pier 3 in E2 Geological Process

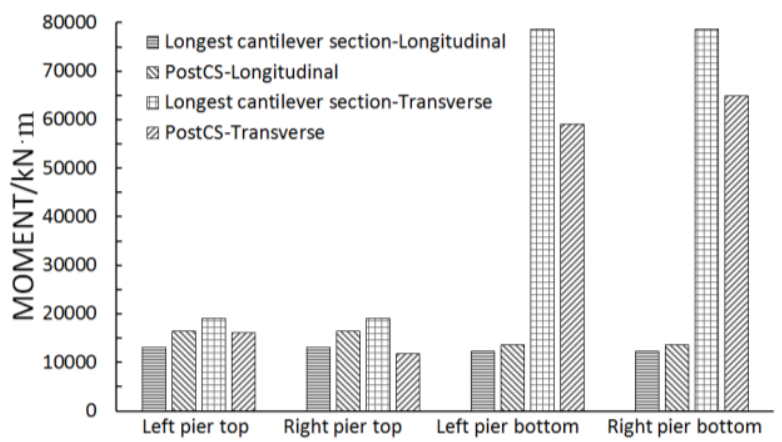

Figure 10. Bending Moment of Pier 3 in E2 Geological Process

\subsection{Seismic Behavior Evaluation}

Generally, strength of bridge beam body satisfies the corresponding requirements in E1 geological process. When an earthquake takes place, piers go wrong in the first place in most cases as they are the weakest positions of the bridge. Therefore, it is necessary to compute buckling and shear strength of the bridge pier [12]. The most unfavorable combination of E2 seismic action effect and permanent action effect was selected for pier strength checking. Relevant checking outcome has been given in Figure 11 and computational results of displacement on pier top presented in Figure 12. As demonstrated by these computed results, pier strength of the bridge in E2 geological process meets the requirement of the code; displacement on pier top also falls in its permissible range; and, dynamic behavior and seismic behavior of the structure are both satisfactory.

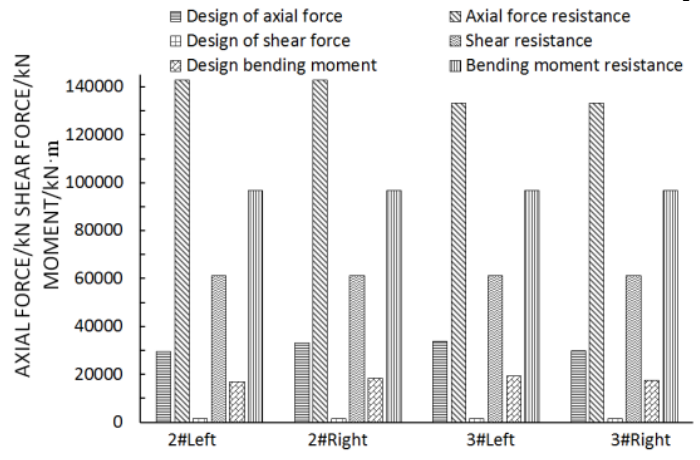

Figure 11. Pier Strength Checking in E2 Geological Process

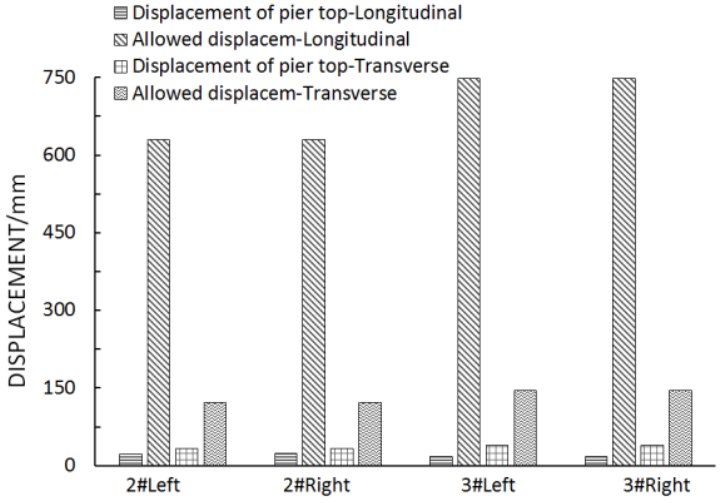

Figure 12. Displacement Checking for Pier Top in E2 Geological Process

\section{Conclusion}

In this paper, three-span pre-stressed concrete continuous rigid frame bridge was analyzed to establish a three-dimensional finite element model; then, static and dynamic characteristics of the bridge with its seismic behavior were analyzed by considering the soil-pile interaction. Major conclusions can be drawn as follows:

- Internal force of large-span pre-stressed concrete continuous rigid bridge is generated by gravitational force of the structure and the pre-stress. Under the circumstance that structural design is conducted for full bridge, internal force checking specific to sections near the pier top and on the mid-span should be enhanced.

- Seismic response analysis was performed for the bridge by a response spectrum method and time history analysis. Relevant computed results signify that the former is more conservative than the latter. For the cause of structural safety, the response spectrum method was utilized in this paper for seismic performance design and checking of the project.

- For continuous rigid frame bridge, seismic directions taken into consideration during structural seismic analysis at different construction stages are different. Dominating factor of Pier 3 is the internal force incurred by earthquake along the axial direction of the completed bridge; in the maximum cantilever state of construction, however, internal force of Pier 3 is generated by earthquakes in the transverse direction of the bridge.

- Regarding checking of displacement on pier top and the pier intensity checking by means of the most unfavorable combination of earthquake action effect and permanent action effect, their results meet the code requirement, which manifests that dynamic and seismic behaviors of the structure are high.

\section{References}

1. Sh.X. Zheng, Sh.Zh. Xi, J.Zh. Yang, J. Southwest Jiaotong Univ. (6), 14(1997)

2. D.Sh. Zhu, Sh.Zh. Liu, L.S. Yu, Chin. J. Highw. Transport 15(3), 44 (2002)

3. Q. Li, K.H. Wang, H. Wei, Earthq. Eng. Eng. Vibrat. 26(3), 74 (2002) 
4. D.Q. Shen, G.H. Cui, C.G. Wang, Subg. Eng. (1), 107 (2001)

5. H.Ch. Fu, Nort. Jiaotong (3), 66(2012)

6. L.L. Yu, J.J. Wang, Highw. Eng. 33(1), 36(2008)

7. Sh. Feng, Y.Q. Xiang, J.F.Wang. Highw. Eng. 30(4), 77(2005)

8. B. He, H.P. Zhu, Y.N. Shi, Highw. 35(11), 1(2007)

9. B. Wang, H.L. Zhang, F. Xu. Highw. Eng. 32(4), 28(2007)

10. X.J. Ning, Y.T. Zhou, R. Li. J. Kunming Univ. Sci. Tech. (Natu. Sci. Edit.) 32(3), 64(2007)

11. H.L. Zhang, B.X. Zhang, Highw. (7), 210(2014)

12. J.Q. Lei, L.X. Song, J. Beijing Jiaotong Univ. (1), 1 (2012) 